\title{
REGULATING THE TIMING OF URBAN DEVELOPMENT
}

\author{
HENRY FAGIN*
}

Coordination, a major aspect of planning, involves space and time. Effective urban planning demands a simultaneous attention to both.

In the past half-century a static attempt at space coordination has become widespread. Its essence is expressed in certain dictionary definitions of the noun plan: "a representation drawn on a plane" or "a scheme of arrangement." The master plan, the comprehensive plan, the zoning plan frequently are interpreted as embodying an ideal and ultimate balance among districts of land classified as residential, commercial, and industrial. Since this conception deals with the what irrespective of the when it represents what I term static space coordination.

A dynamic approach to space coordination is suggested by other dictionary definitions of plan: "a schematic program indicating parts in their arrangement," "a method of action." Here we shift from dealing mainly with ultimate categories and patterns of land use to considering the activities involved in urban development. This latter approach stresses the coordination of programs of action. It relates industrial, business, service and residential construction activities; it coordinates the variety of activities that extend the urban transportation system; and it relates all these to the activities that utilize parcels of land.

The evolving demands on urban planning already have forced a shift in focus from the map to the program of action. The ultimate master plan map as the goal of planning is being replaced by a "planning process" conception in which the master plan is regarded as an open-ended sequence of plans describing at each successive point in time a desirable equilibrium among ever-changing activities. Any single map in the series represents a cross-section cut through the community at some critical instant in time-a concatenation little likely to be repeated at any other time. (One eminent city administrator now uses the term "forward programming" in place of "master planning.")

Necessarily, this conception of urban planning involves coordination in time as well as space, of programs as well as land areas. Capital budget programming is a start, but deals only with a small portion of a large problem. It is my belief that until the science of planning invents greatly improved methods for regulating the timing of urban development, many attempts at space coordination must con-

* B. Arch. I937, M.S. in Planning and Housing, I938, Columbia University. Planning Director, Regional Plan Association (New York) since January 1952. Planning Director, Northern Westchester Joint Planning Program, r949-195I. Author, Problems of Suburban Communities, in AMenican Society op Planning Officials, Planning-1951 63. 
tinue to fail-master plans remaining unrealized, zoning ordinances ineffectual and rapidly obsolescing. Static space coordination is not merely inferior, it is impossible in a dynamic world.

\section{Time Coordination}

Coordination in time has two aspects. Tempo, the rate of urban development, is the first. The Borough of Mountain Lakes, New Jersey, which has acquired most of its remaining developable land and sells a limited number of building lots annually, is regulating the absolute tempo of its growth.

Moses Lake, a city in the state of Washington, makes the tempo conditional on certain future events. In the proposed Moses Lake "reclamation zone," certain lands may not be utilized for buildings until they have been filled in accordance with established grades. Already the city has refused to approve a subdivision plat for lands within one area subject to flooding.

The statutes of Washington empower a planning agency to disapprove a subdivision not in the public interest. According to Floyd M. Jennings, planning consultant to the Association of Washington Cities, this proviso "has not been adjudicated in the State of Washington, to the best of [his] knowledge. . ." However, a number of cities have adopted subdivision ordinance provisions specifying that:

Land, which the planning commission has found to be unsuitable for subdivision due to flooding, bad drainage, steep slopes, rock formations, or other features likely to be harmful to the safety, health, and general welfare of the future residents, and which the planning commission considers inappropriate for subdivision, shall not be subdivided unless adequate methods are formulated by the developer and approved by the city engineer.

Mr. Jennings writes that "None of these local experiences have been adjudicated by a Court of Record or by a lower court in this state."

Sequence is the second aspect of time coordination. It is exemplified in a zoning ordinance under active consideration in Clarkstown, New York. In this ordinance there will be an attempt to encourage growth around existing settlements before opening additional lands to intensive use.

To carry out this program, some areas, placed at first in one-acre residence districts, are designated on the new zoning map for change to the $1 / 3$-acre district. Specific conditions must be found to exist before such changes will be made, but changes in these areas shall have priority over those in other areas. Thus, within the general reserve of two-acre and one-acre open land, certain districts will be available immediately for intensive development while other specifically designated and mapped areas will become available after the initial lands near full utilization. This will tend to bring about a planned sequence of land development at designed densities.

Existing measures affecting the timing of urban development appear to be motivated by a number of considerations-not all of them, to be sure, equally valid in social, economic or legal terms. For instance, acreage zoning and minimum-size 
dwelling regulations when carried to excess; obsolete building code requirements retained mainly to maintain a high local cost of new construction and thereby to discourage new tax burdens; controls over dwelling appearance which hamper largescale or prefabricated building operations-all these tend to slow the rate of growth, though they are intended primarily for other purposes.

Five Planning Bases for Timing Control

But there are at least five well-considered motivations for regulating the timing of urban development. These derive from the specific nature of modern communitybuilding activities and community requirements:

I. The need to economize on the costs of municipal facilities and services. These costs are strongly affected by the sequence in which the different areas of a municipality are developed. This matter involves the efficient provision of police and fire protection, schools, bus lines, streets and highways, utilities, and other important facilities. The sequence of building operations determines, for example, whether linear facilities such as pipes and streets will have to be extended inefficiently over long distances to serve scattered users or will be extended gradually to serve areas built in careful phase with efficient facility growth.

The order in which the parts of a large community are built affects both the initial expense of facilities and their costs of maintenance and operation. Largescale builders like the Levitts place great emphasis in their construction operations on careful scheduling for the most economical possible sequence of development, section by section. The proposed Clarkstown regulations discussed above are intended to reduce long-term municipal expenses.

2. The need to retain municipal control over the eventual character of development. For example, the desired over-all future town pattern may require intensive development served by public sewer and water lines in an extensive valley at present remote from any utility lines. If there is no control over the timing of building, however, the area in question may be the early subject of a substantial amount of low-intensity construction served by individual wells and separate sewage disposal fields. The existence of this type of development may later make it impossible to convert the valley to the more intensive character required by the evolving municipal pattern, even though important community-wide reasons exist for doing so. In similar fashion, an important future industrial area may become so cut-up by scattered small-scale factories as to preclude its eventual development as a planned, coordinated industrial district when the time is ripe.

3. The need to maintain a desirable degree of balance among various uses of land. For example, it is essential to the economic stability of certain municipalities which contain large areas of low-value homes that the service costs be offset by tax income from commercial and industrial ratables. In such places it is essential that new residential construction be timed in proper relation with business and industrial expansion. 
Another sort of balance involves the subtle relationship of areas of varied character. The village of Hastings-on-Hudson in New York has a policy exercised through the zoning ordinance which regulates the timing of apartment construction in relation to the rate of one-family home building in accordance with a 15 to 85 ratio. Thus, for instance, whenever 85 new one-family dwellings have been built, the village may issue permits enabling 15 dwelling-units in apartment buildings. This regulation is intended to maintain what is locally felt to be a desirable predominance of one-family dwellings in a commuter village, but at the same time to make possible a necessary though smaller supply of rental apartments. The device makes the timing of one element conditional on the timing of another related element.

4. The need to achieve greater detail and specificity in development regulation. The growing awareness of this need is evidenced by the trends in zoning towards increased use of special permit devices subject to detailed requirements and conditions and by the popularity of "designed-district" provisions.

In Great Britain a desire for greater sensitivity of controls led to the present system of development permissions instituted after country-wide public acquisition of "development rights." Local authorities may grant or withhold permission to build, according to the needs of a development plan. At least in the negative sense-that is, being able to prevent development unless it accords with a municipally determined time schedule-the British regulations illustrate an application of control over timing to enable specific conformity with a detailed municipal plan. Under the British controls, for example, on a specific site in a developing area, permission for a store building may be denied on one day if the planning authority considers the construction premature, and at a later date permission may be granted.

There is, of course, a direct but generally unrecognized counterpart to this in the United States. Commonly, a municipality, petitioned to rezone a residential tract for a regional shopping center, refuses to do so when requested, but later decides the propitious moment has arrived and enacts the necessary amendment.

So long as zoning practice provided roomy districts, each with a capacity for more than the expected amount of pertinent development, the element of time was unimportant. With the current trend to specific changes for specific projects, however, timing has become an integral element in zoning administration. Occasionally, indeed, special zoning amendments and special use permits are so drawn as to become null and void after a specified period of time if construction has not commenced.

5. The need to maintain a high quality of community services and facilities. This requires during periods of rapid building expansion that adequate intervals of time be assured for the assimilation of residential, business or industrial additions to the community.

When newcomers are added faster than municipal facilities and services can be 
increased, the resulting overloads on existing capacities cause a decline in the quality of services. Uncontrolled, this deterioration can result in seriously substandard levels of water supply, sewage and waste disposal, public school education, and public recreation. Moreover, if the rate of sudden and unanticipated shopping or industrial expansion outstrips the pace of highway improvement, residential streets may be flooded by excessive traffic seeking to by-pass congestion. (It is possible that adequate time for the social integration of incoming families represents a sixth legitimate basis for regulating community. growth.)

Sands Point, New York, has adopted a means of partially regulating the rate of residential development to keep it in reasonable relationship with community facility and service capacities. In the Sands Point zoning ordinance, land subdivision is defined as a business use, permitted in residential districts only on special permit. The village planning board in connection with its review of each subdivision is required to make a finding as to the village's capacity to absorb the proposed new lots. If deemed appropriate, the subdivision approval may be accompanied by a limitation on the number of lots for which building permits will be issued in any one year. The planning board is empowered at its discretion to limit building to 20 per cent of the approved lots in each of the next ensuing five years.

Toward a More Solid Framework for Regutiating the Timing of URBAN DeVELOPMENT

Motivated by the foregoing five planning bases for timing control, it is possible to design reasonable and workable regulations affecting both the sequence and the tempo of building operations. The following suggestion sketches one possible approach to such regulations.

\section{A. Zones of Building Priority}

Under the system of controls suggested here, the zoning map is derived from the series of land use maps that comprises the master plan sequence described above in the first section. It shows all lands in the specific use, density and bulk district designations determined appropriate by the local governing body. These designations embody the best current thinking as to the most desirable municipal pattern. Land for which a specific designation cannot yet reasonably be made is placed in a largeacreage "reserve district," from which portions are assigned to particular districts from time to time.

Superimposed on these basic districts, however, is an additional set of building sequence districts called zones of building priority; and these range from first priority to last priority through an appropriately numbered series. Building permit applications are granted in the order of the zones of building priority and within each such zone in the order of application dates.

The assignment of particular zones of building priority expresses the sequence of development most advantageous to the municipality for economizing on municipal 
costs and for securing the desired character of development-bases (I) and (2) above.

\section{B. Regulating the Tempo of Building}

The availability of building permits under the suggested controls is determined separately for each broad zoning classification-close and open type residence, business, manufacturing, etc. The number of permits available from time to time is derived from: findings as to the current balance among different types of development-basis (3); findings as to the status of specific private and public projects proposed to be encouraged by the municipality in the public interest-basis (4); and findings as to the current capacity to assimilate the proposed structures in view of the progress of municipal programs for facilities and services-basis (5).

A municipality exercising this system for regulating the timing of urban development should be obliged by statute to carry forward programs of municipal facility and service expansion reasonably related to development trends so as not to block the utilization of land but to expedite it in orderly fashion. A developer of land should have the opportunity of improving the building priority rating of his land by offering to construct off-site facilities and to provide services needed for proper development, but not yet feasible of municipal programming.

Undoubtedly, the institution of systematic controls over the timing of development will affect the market value of various parcels of land-some upward, some downward-but this has always been true of measures taken under the police power. Possibly, in certain municipalities each parcel of land in separate ownership on the effective starting date of the regulations will be considered entitled to one building permit irrespective of priority zone; and perhaps in rural areas building permits will be granted irrespective of priority zone in all applications involving very large lots -five or ten acres or more per structure.

Viewing the municipality in its entirety, the advantages of wisely exercised time regulation for shaping and achieving superior urban patterns will afford a greatly increased property value for the total of all land. After a period of readjustment, new value levels will reflect the real utility of the land, and ad valorem taxes will distribute the burdens of municipal service costs accordingly.

In occasional specific circumstances some form of compensation possibly will be warranted to offset individual losses. This may follow the Mountain Lakes precedent of municipal purchase at fair present market value; with respect to vacant tracts it may entail differential tax rates as between the different zones of building priority; it may involve a municipal option to buy agricultural land after a stated period of continued farming use; or it may involve adapting the British method-municipal purchase of development rights.

In general, however, the mass of mounting evidence eloquently argues that regulating the timing of urban development is a valid and necessary exercise of the 
police power. Such regulation not only is permissible in the legal sense but has become an urgent responsibility of municipal government needed to protect the very health, safety, and welfare of our rapidly growing suburban communities. In the light of planning theory as expounded in this paper and of the accumulated experiments of municipalities throughout the nation, it is clear that tempo and sequence zoning administered pursuant to soundly based municipal planning policy and in accordance with reasonable regulations will be powerful aids toward improving the quality of our communities. 